\title{
Mapping raindrop erosion of GFRP composite wind turbine blade materials: perspectives on degradation effects in offshore and acid rain environmental conditions
}

\author{
Ghulam Rasool, Anna C Middleton, Margaret M Stack \\ Department of Mechanical and Aerospace Engineering \\ University of Strathclyde - James Weir Building \\ 75 Montrose Street, Glasgow G1 1XJ \\ United Kingdom
}

\begin{abstract}
Climate change is rapidly forcing the world to create renewable energy that is capable of sustaining future energy requirements globally. The generation of renewable energy at a comparatively lower cost is a major challenge for this industry. Unforeseen weather conditions and environments such as offshore conditions or involving acid rain have a significant effect on the degradation of structural materials of renewable energy devices. For the investigation of droplet erosion behaviour of the advanced material for the wind turbine blades, experimental work was carried out on a glass fibre reinforced epoxy (GFRE) composite in different environments. A whirling arm rig was used for this experimental work in a laboratory simulated rainfall conditions at a constant tip speed of the rotor blade. Three types of rainwater were used for a range of angles of attack from 15 to $90^{\circ}$ in an increment of $15^{\circ}$. Erosive wear maps have been constructed to show the weather, location, environment and raindrop erosion effects on the degradation of the wind turbine blade material. This map predicts that erosion in saline and acidic rain conditions act synergistically on the blade material, which results in delamination between the fibre layers, pit formation, and development of micro stresses leading to loss of adhesion of reinforcement fibres.
\end{abstract}

Keywords: Wind turbine blade, GFRE composite materials, Raindrop erosion, Impact angles, Acid rain 


\section{Introduction}

The generation of electricity by a wind turbine is significantly affected by its location, weather, and environments. A wide range of factors, such as sea water conditions, presence of pollutants, acid rain conditions, hailstones, extreme temperature, solid particle, insects, rain, and wind contribute to the degradation of blade material by erosion in a synergistic manner. These factors result in failure of wind turbines by the degradation of the rotor blade. The rotor blade is an important component of a wind turbine which converts the wind energy into a mechanical one to rotate the electric generator shaft. The leading edge of the rotor blade is generally affected by erosion, which results in damage and roughening of the exposed surface and aerofoil of the blade. A damaged aerofoil leads to an increase in drag forces on the blade surface, which results in a compromise in the performance and decrease in efficiency of the wind turbine in a very early stage of its service life. Leading-edge erosion of the wind turbine blades has been increasing interest in research due to the implications it has on the rapidly growing wind energy industry [1].

To increase the share of wind energy, designers and manufacturers have focused on a longer rotor blade of the turbine, which will preferably be operated in an offshore environment. This approach has raised new challenges for the selection of a durable, lightweight, high strength to density ratio material for the rotor blade, which can withstand degradation in an aggressive and harsh environment. For mitigation of these challenges, wind turbine manufacturers are using fibre-reinforced polymeric composites for the manufacturing of large rotor blade. These composites have good mechanical and chemical properties and higher strength to density ratio.

In the offshore areas of the UK, the average wind velocity is $14 \mathrm{~ms}^{-1}$. The high velocity along with the higher tip speed of a rotor blade, raindrop erosion becomes more significant for a rotor blade, which affects the quality, performance, and durability of the blade material [2]. At higher tip speed raindrop impacts can result in up to $25 \%$ decrease in the coefficient of lift and a minimum of $60 \%$ increase in the coefficient of drag [3]. Acidic pollution, saline atmosphere, and raindrop impact with erosion synergistically on the blade material, which enhances the mass loss, damage of the exposed surface and mass gain during operation of the wind turbine [4-6]. 
The effect of acidic rain on the wind turbine blade is an emerging area of interest and there is little research work available in the literature on this issue. However, with the extended use of glass fibre reinforced composite in corrosive environments there is significant research work which can be adapted to predict the effects of acidic rain on leading edge erosion. Several researchers have worked on the effects of acidic rain on mechanical and chemical properties of the polymer and fibre reinforced polymer composite materials. Joeng-Ho Kim et al. [7] carried out research on the effect of acid rain on the tracking resistance of polymer insulation. They concluded that the tracking resistance of various polymeric materials reduced from 30 to $50 \%$ in an artificial acid rain solution. Moreover, the reaction of acidic solution results in the mass loss by decomposition resulting in roughening and exposing the surface, which leads to a decrease in contact angle. A rough and porous surface can easily absorb acidic rainwater by diffusion [7].

Amaro et al. [8] researched the effects of alkaline and acid solutions on glass fibre epoxy composites (GRP) in particular for mechanical properties such as flexural and the impact strength by immersing this material in hydrochloric acid $(\mathrm{HCl})$ and sodium hydroxide $(\mathrm{NaOH})$ solutions. They observed that the flexural strength and modulus of elasticity of this material decreased significantly with an increase in immersion time. Ultra-micro indentations appeared on the exposed surface, which affect the polymeric matrix mechanical properties as well as the surface roughness of the specimen. They concluded that the resistance to repeated low-velocity impacts was dependant on the solution and the immersion time. The elastic energy of the specimens decreased with an increase in numbers of impact, which resulted in an increased damage area. The specimens gained mass by diffusion, which leads to swelling of the matrix. The swelling results in the development of micro stresses and pit formation within the composite material [8].

The literature shows that the polluted environment and acidic rain act synergistically in the degradation of the wind turbine blade. The erosion resistance of polymer composites is affected by the changes in mechanical properties [9]. The leading edge erosion of the rotor blade increases with the exposure time in this environment. Such erosion processes of the rotor blades can become a major issue even within 2 years of their operation [10]. 
Moreover, droplet water hammer effects result in the development of local pressure and wetter jetting, which result in damaging the exposed surface of the blade. The compressible water hammering effect is several times greater than the jetting pressure, which can easily exceed the yield strength of the blade materials. The erosion process is driven by the impact velocity, angle of attack, frequency of droplet, and droplet size. The erosion process progresses through three stages, i.e. incubation, increasing and decreasing, and placid (steady) period. These stages depend on the changes in the exposed surface topography, microstructure, erosion resistance properties, and exposed environment [11]. The exposed surface topography plays an important role in the erosion behaviour of the material in the increasing period. After the increasing stage of erosion, the erosion decreases significantly when it enters the placid period $[12,13]$.

In this paper, a laboratory simulated wind turbine blade composite material test results have been presented to highlight how the different types of raindrop solution and varying impact angles can affect the leading edge erosion. The exposed surfaces have been examined by using Scanning Electron Microscopy techniques to investigate the erosion mechanisms involved in the degradation process of the rotor blade material. An erosion map has been constructed for the test results of various types of rainwater versus impact angles to investigate the failure of wind turbine blade material. The wear map predicts that the saline and acid rainwater act synergistically with leading edge erosion of the GRPE composite rotor blade. The delamination between the fibre layers, pit formation, development of micro stresses, cracks, and exposure reinforcement fibre were identified as contributing to the the raindrop erosion mechanisms.

\section{Experimental}

\subsection{Test Rig}

A whirling arm apparatus (raindrop erosion test rig) was used for this experimental work to simulate laboratory wind turbine blade conditions Fig.1. The rig consists of a steel drum in which two arms rotate Fig. 1 (a). The samples are mounted on the ends of both arms in sample holders Fig. 1 (b). The rig has the provision of variable tip speeds. The water is provided through tubes to hypodermic needles, which are connected at the end of tubes and rain solution is fed from a peristaltic pump. Needles are placed evenly above the samples 
trajectory of rotation. The output of the pump could be adjusted to get the different flow rate, droplet size, and droplet frequency to simulate with light, moderate and high rain conditions. An alternative current motor is installed underneath the steel drum, which rotates the rig arms through the shaft. Perspex tubes are installed around each needle to make sure that droplets fall vertically, undisturbed, without the interference of air and have a proper impact on the specimen Fig. 1 (b).
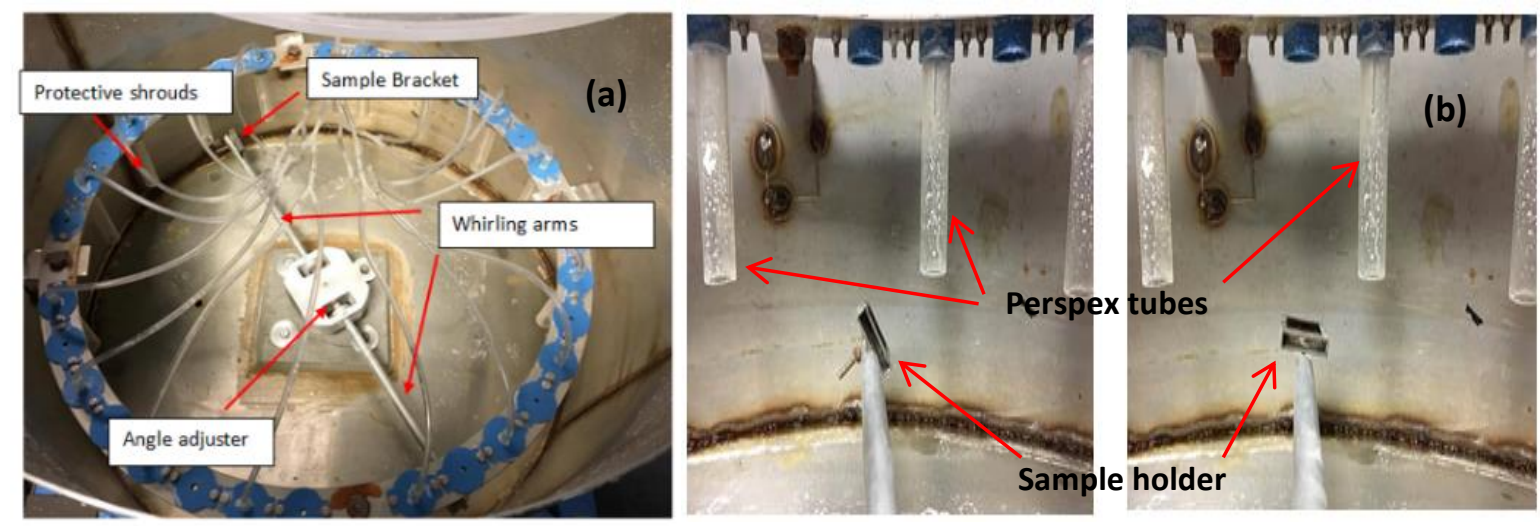

Figure 1: Raindrop erosion test rig, a) testing mechanism inside the drum, and b) protective shroud on needle device.

\subsection{Material}

It is vital that wind turbine blades meet a high standard of criteria to perform well in the vast range of environmental conditions. The rotor blade material must have;

1. High material stiffness to maintain optimal aerodynamic performance

2. Low density to reduce gravity forces

3. Long-fatigue life to reduce material degradation

A glass fibre reinforced epoxy (GFRE) composite was used to simulate a modern-day wind turbine blade material in this experimental work. This composite was manufactured at the University of Strathclyde. It comprised a total 15 fibres with 5 sheets of tri-axial orientation, schematic Fig 2(a). The stress distribution of the specimens is shown in Fig. 2(b). The exposed surface of the specimen is shown in Fig. 2(c). The samples were cut into $30 \mathrm{~mm}$ squares using a 'Struers Discotom 2' which has a fully enclosed cutting chamber with an external recirculation tank to avoid fibres being released into the air reducing the risk of inhalation. The mechanical properties of this composite are shown in Tab. 1. 

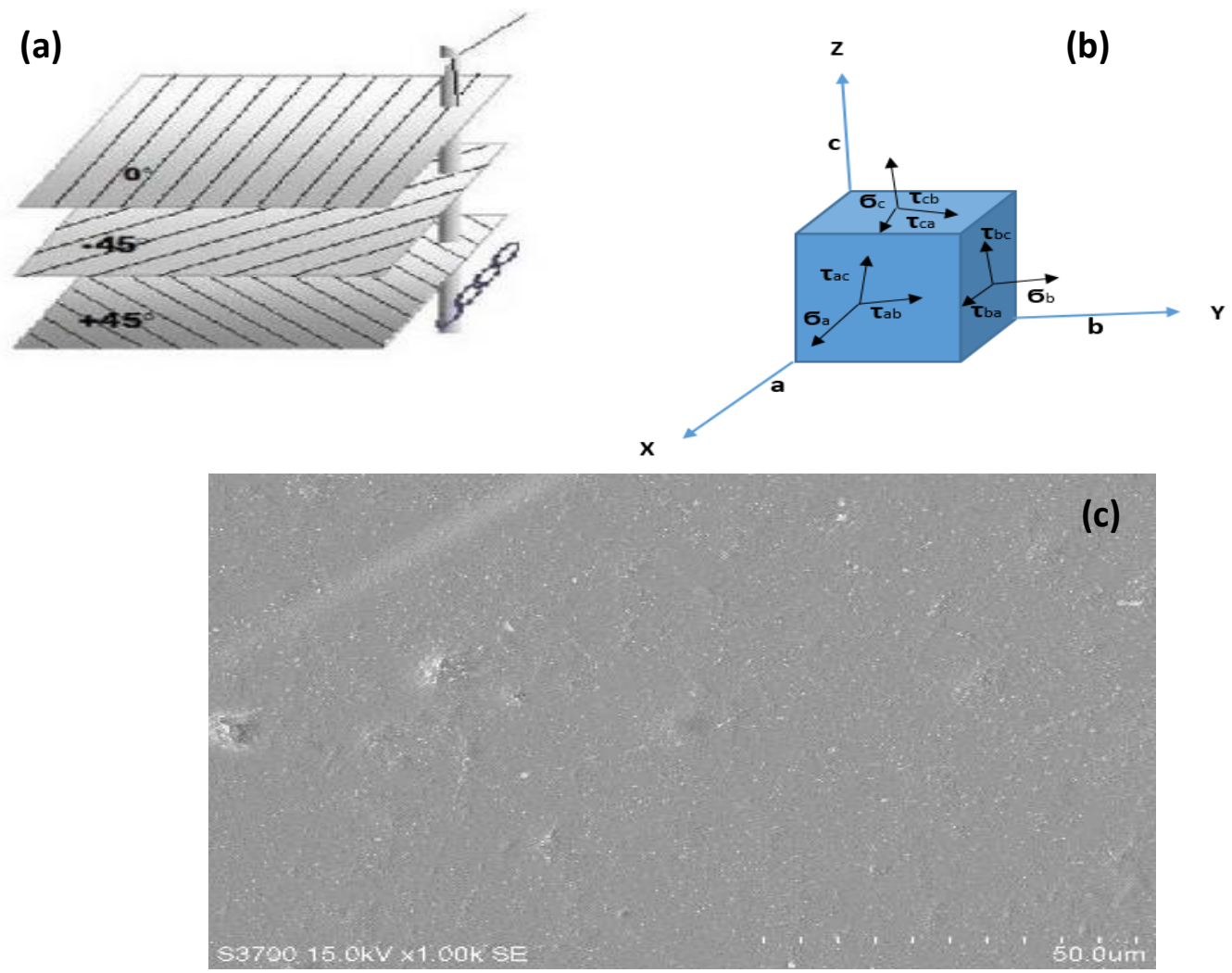

Figure 2: GFRE composite material (a) Schematic of composite sheet layers, (b) Schematic of stress distribution of the composite material, and (c) SEM image of the specimen before test.

Table 1. Mechanical properties of GFRE Composite [14]

\begin{tabular}{|lc|l|}
\hline Material Parameter & & Values \\
\hline Density $\left(\mathrm{Kg} \mathrm{m}^{-3}\right.$ ) & $\boldsymbol{\rho}$ & 2004 \\
\hline & $\boldsymbol{E} a$ & 33.4 \\
Young's Modulus (GPa.) & $\boldsymbol{E} b$ & 16.4 \\
& $\boldsymbol{E} c$ & 14.2 \\
\hline & $\boldsymbol{V}_{b a}$ & 0.227 \\
Poisson's Ratio & $\boldsymbol{V}_{c a}$ & 0.0796 \\
& $\boldsymbol{V}_{c b}$ & 0.274 \\
\hline \multirow{3}{*}{ Shear Modulus (GPa.) } & $\boldsymbol{G}_{b a}$ & 9.73 \\
& $\boldsymbol{G}_{c a}$ & 4.86 \\
& $\boldsymbol{G}_{c b}$ & 4.83 \\
\hline Shear Strength (MPa.) & $\boldsymbol{\tau}_{a b}$ & 97.2 \\
& $\boldsymbol{\tau}_{a c}$ & 97.2 \\
& $\boldsymbol{\tau}_{b c}$ & 97.2 \\
\hline & $\boldsymbol{\sigma}_{a b}$ & 253 \\
\hline & $\boldsymbol{\sigma}_{a c}$ & 73.5 \\
& $\boldsymbol{\sigma}_{b c}$ & 73.5 \\
\hline Censile Strength (MPa.) & $\boldsymbol{C}_{b}$ & 123 \\
& & \\
\hline
\end{tabular}




\subsection{Rainwater solution}

The main objective of the experimental was to investigate the effects of different possible rainwater solutions on wind turbine blades. Three series of experiments were carried out with different solutions, which are as follows:

1. Deionised water, $\mathrm{pH} 7$, was used as a control liquid in the first test.

2. Artificial acidic rainwater of $\mathrm{pH}$ 4. To maintain this $\mathrm{pH}, 0.5 \mathrm{ml}$ of acid per $25 \mathrm{I}$ water was used. (Due to limitations on resources the acidic rain was simulated by combining tap water and an equal blend of sulphuric and nitric acid).

3. Saltwater of $\mathrm{pH}$ 8.1. To maintain this $\mathrm{pH}, 3.5 \mathrm{~g}$ of $\mathrm{NaCl}$ dissolved in $100 \mathrm{ml}$ of water, i.e. $3.5 \%$ $\mathrm{NaCl}$ by weight to simulate seawater.

\subsection{Impact angle}

The tests were carried out at $15^{\circ}$ to $90^{\circ}$ angle of attack with an increment of $15^{\circ}$. Each arms have the provision of twisting at different angle positions. The test was not carried out $0^{\circ}$ as it was expected that the water droplets would hit the metal brackets instead of the specimen.

\subsection{Water droplet size}

Water droplet size was kept constant by using the same size needles and the flow rate of the peristaltic pump through all 16 tubes. 23 gauge hypodermic needles were used which produced a water droplet of average $2.5 \mathrm{~mm}$ in diameter Fig. 3.

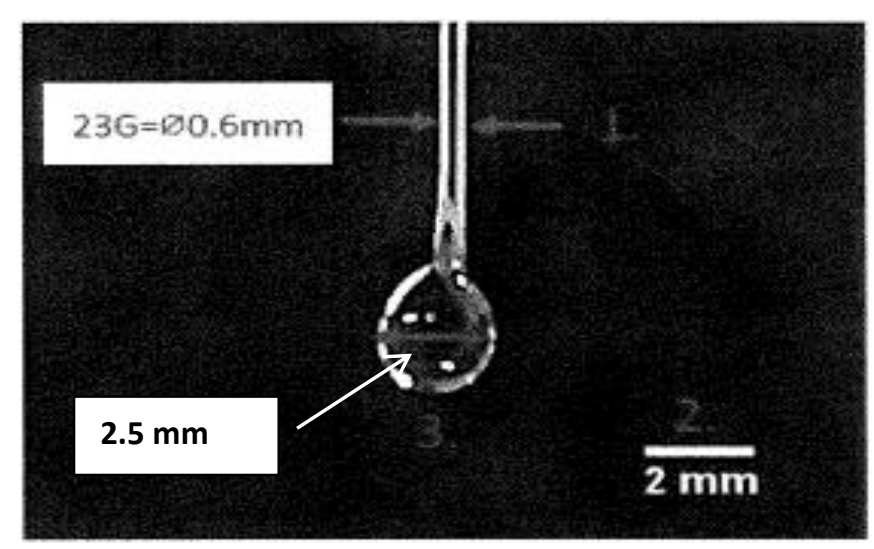

Figure 3: raindrop needle and raindrop size 


\subsection{Flow rate}

The feed-water pump (peristaltic pump) used was calibrated to ensure that each needle produced the same size droplet to achieve the desired rainfall rate, which was to be $25.4 \mathrm{~mm}$ $\mathrm{h}^{-1}$. This is a standard rainfall rate for experimental purposes [15].

\subsection{Tip speed and test time}

To observe the effects of various rainwater solutions in conjunction with impact angles, the tip speed of the specimen blade was kept constant for the series of tests. Due to the limitation of the test rig, experiments were carried out at a constant rotor blade tip speed of $60 \mathrm{~ms}^{-1}$. Each test was run for 30 minutes.

\subsection{Wear measurement}

All test samples were weighed three times to get an average weight before and after the experiment run by using an electronic balance with an accuracy of $10^{-4} \mathrm{~g}$. Moreover, other post-test analyses, such as SEM and EDX were also carried out on Hitachi S3700N tungsten filament SEM machine to investigate the topography and contamination leftover on the exposed surfaces. The samples were sputter-coated with gold to allow the samples to conduct to get a clear image. A carbon gum was applied to the edge of the samples to prevent charge accumulation.

\section{Test results}

\subsection{Mass variation}

Figure 4 shows the mass variation of the GFRE polymeric composite due to raindrop erosion of three solutions at different angles of attack. This figure shows that the trend of erosion is varying and fluctuating in the mass loss for each solution and angle of attack. This material is not showing any specific traditional erosion behaviour, i.e. the erosion peak patterns of a higher mass loss at $30^{\circ}$ for so-called ductile materials and higher mass lass at $90^{\circ}$ for so-called brittle materials. It is acknowledged that these mechanisms can interchange depending on the shape of the particle and the characteristics of the impact [16]. 


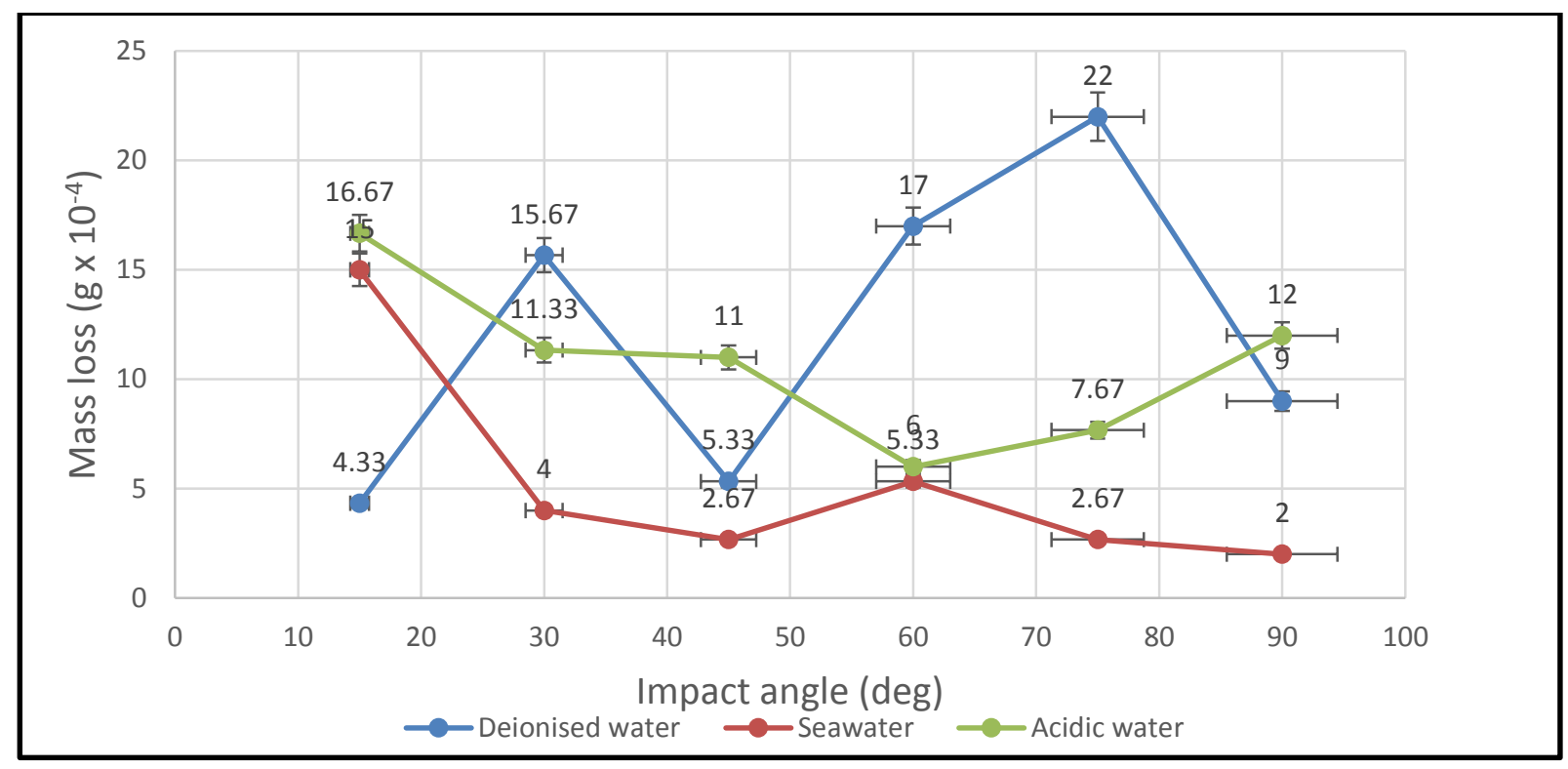

Figure 4: Mass variations vs raindrop Impact angle for different rainwater solutions

\subsection{SEM micro-graphs and EDX analysis}

Figure 5 shows the SEM images of the exposed surfaces after the test carried out in different solutions. These images clearly show the degradation of the exposed surfaces in these solutions. The mechanisms of the damage, i.e. indentation, gouges, cracks, blister, and exposed fibres are clearly visible in figures $5(a, b, c)$. Figure 6 shows the clear degradation of the specimen by cracks spreading across the centre and flaking away of material from the exposed surface in acidic water.

Figure $7 \& 8$ show the salt crystals retained on the exposed surface during the tests with a saline solution. Table 2 shows the results EDX analysis of the two spots in figure 7, which are showing $30.04 \%$ and $36.30 \%$ sodium and $69.96 \%$ and $63.70 \%$ chloride retained in the composite. Saltwater absorbed by diffusion during the test results in comparatively lower mass losses of the specimens in seawater solution Fig. 4 and 8. 

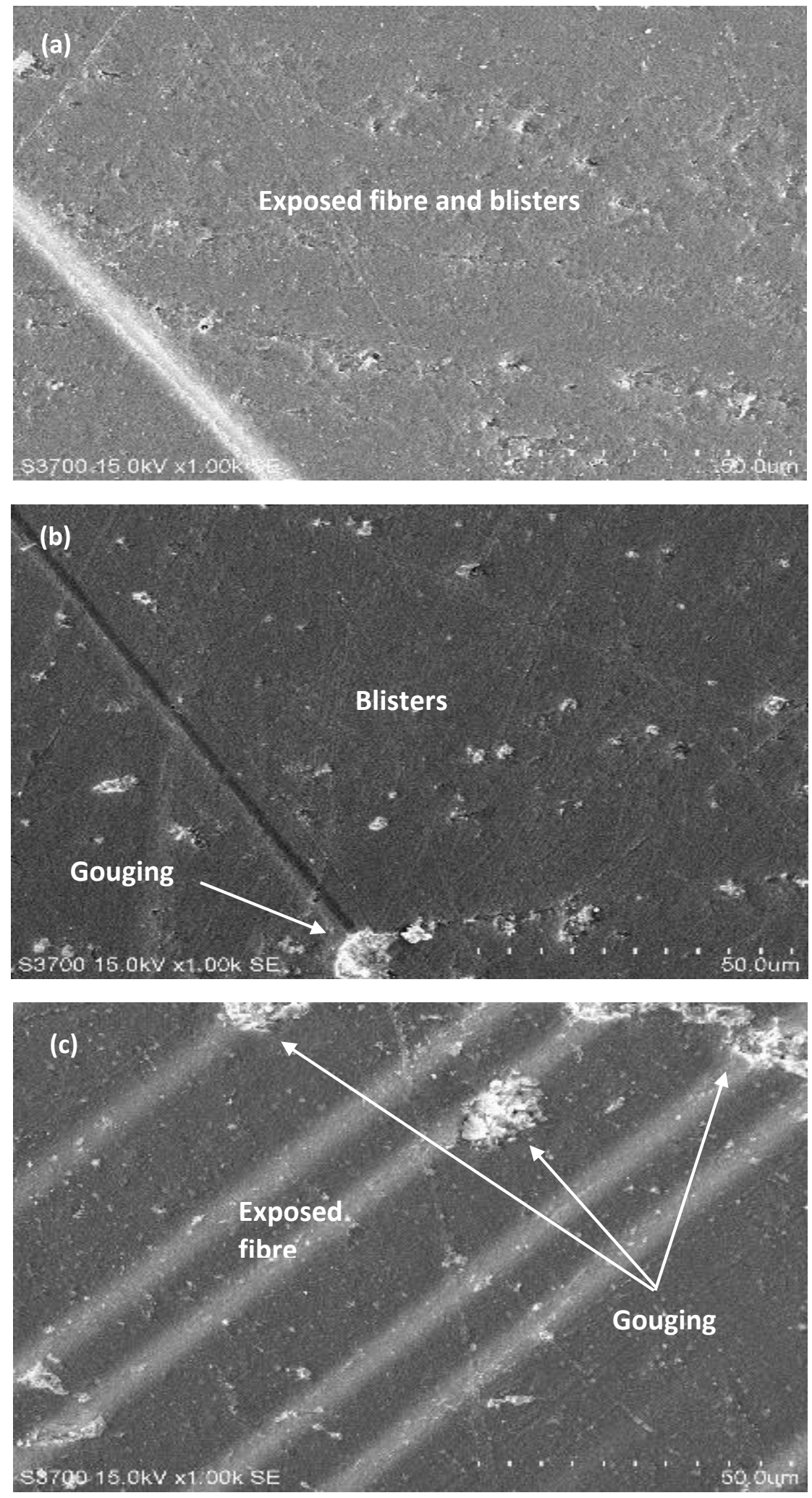

Figure 5: Exposed surfaces of the specimens in different solutions after test, (a) In deionised rainwater, (b) In acidic rain water, and (c) In saline rain water. 


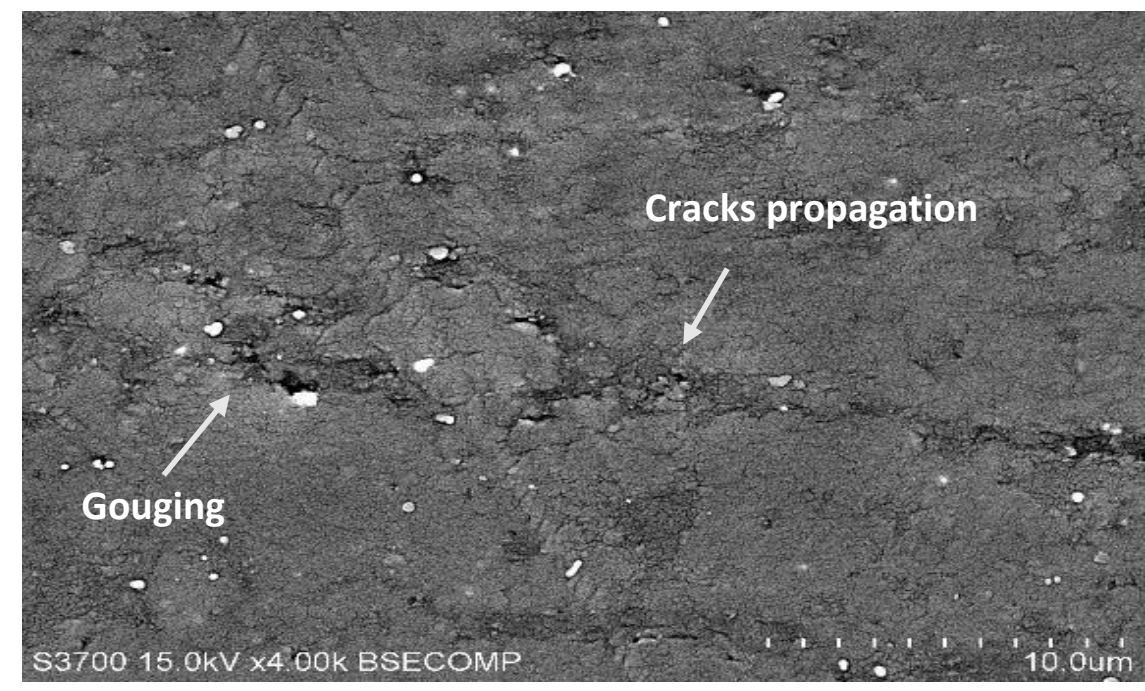

Figure 6: Exposed surface at $90^{\circ}$ with acidic water

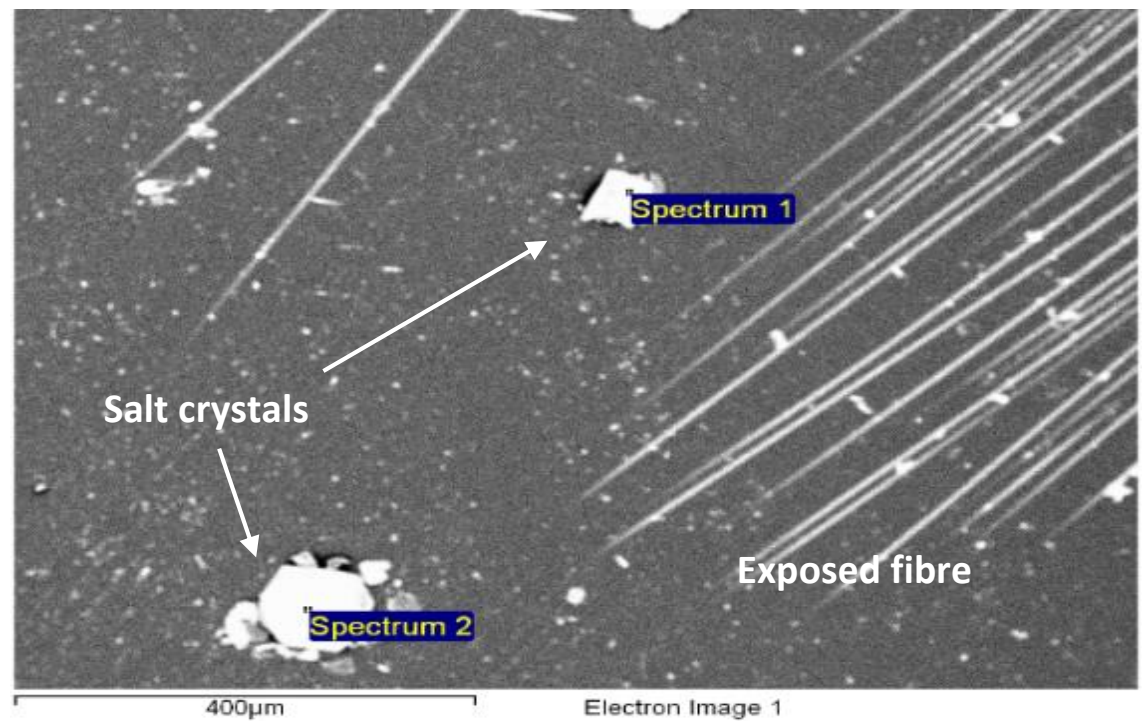

Figure 7: Salt crystals deposited on test sample

Table 2: EDX analysis of the exposed surface of the specimen

\begin{tabular}{|l|l|l|}
\hline Spectrum No. & Na Wt. \% & Cl Wt. \% \\
\hline Spectrum 1 & 30.04 & 69.96 \\
\hline Spectrum 2 & 36.30 & 63.70 \\
\hline
\end{tabular}




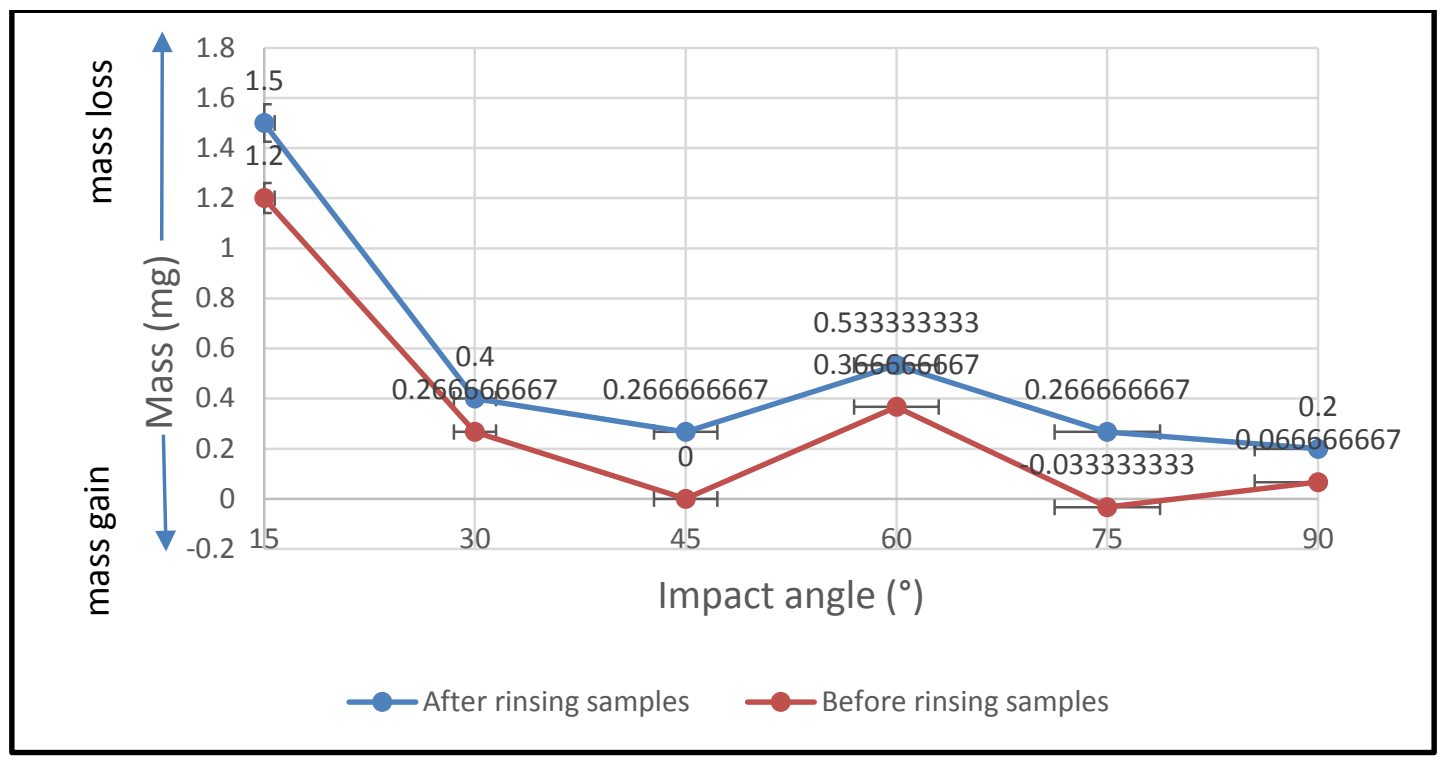

Figure 8 Mass loss vs impact angle with saltwater before and after rinsing samples

\section{Discussion}

The raindrop erosion behaviour of materials depends on various factors, such as material type, exposure conditions, mechanical properties, impact speed, impact angle, and droplet size. The erosion behaviour of this GFRE polymeric composite is fluctuating and is not showing any specific "classical" erosion patterns, i.e. the erosion mass loss peak at $30^{\circ}$ for so-called ductile materials and mass loss peak at $90^{\circ}$ for so-called brittle materials. Contrary to what is observed in the mechanisms of solid particle erosion [17], droplet erosion is controlled by the water hammer pressure and shear forces of the jetting. Furthermore, test results of the erosion for the saltwater solution indicate less mass loss than that of the deionised water and acidic solution. On the other hand, the lower mass loss in the salt solution is attributed to the absorption of salt solution Tab. 2 and Fig. 7 and 8.

In spite of the fact that the GFRE polymeric composites have good matrix-fibre adhesion and low porosity, the saltwater solution was observed to penetrate the composite material. The manufacturing defects in the composite matrix, i.e. pores and voids facilitate the diffusion process and gain of mass. The mass gain leads to deterioration and degradation of the blade material. The moisture reaches the matrix- reinforcement interface rapidly through pores and voids in the composite. The absorbed solution results in blistering, de-bonding of the matrixfibre interface, and exposure of fibre during the droplet erosion, which results in vibration and unbalanced operation of the rotor blades [4-6]. 
On the other hand, the erosion test results for the acidic rainwater and saltwater are showing a similar trend of erosion with higher mass loss at lower impact angles. However, the deionised rainwater droplet impact erosion shows a different trend with a lower mass loss at $15^{\circ}, 45^{\circ}$, and $90^{\circ}$ impact angles and higher mass losses at $30^{\circ}, 60^{\circ}$, and $75^{\circ} \mathrm{Fig}$. 4 . The erosion trend of this composite is not showing any specific typical erosion behaviour for these solutions, i.e. the erosion peak patterns of a higher mass loss at $30^{\circ}$ for so-called ductile materials and higher mass lass at $90^{\circ}$ for so-called brittle. A different erosion trend of deionised rainwater than that of acidic and salt solutions confirms the interaction of these rain solutions on this composite. The material quality is playing a significant role in this erosion process. The erosion peak at $75^{\circ}$ may be either due to the poor quality of this "homemade" material or due to brittle behaviour of this composite at a higher angle of attack. These results are consistent with the research observations found in the literature for erosion fibre reinforced polymer composite materials [3-8,18].

The effect of acid rainwater in water droplet erosion acts synergistically in the degradation process of the blade material, which results in blistering, de-lamination between the fibre layers, pitting, and development of micro stresses within the composite structure Figs. 4 \& 5 (d). The development and propagation of stress-corrosion cracks through the composite dramatically affect the properties of the reinforcement material. The tips of the cracks are prone to a higher chemical reaction in acidic rainwater for metallic materials and analogous behaviour is observed above [8]. On the other hand, the absorption of saline solution and erosion results in a mass gain, blistering, swelling, and de-bonding of the composite matrix and reinforcement fibres by the loss adhesion of the blade material Figs. $4 \& 5$. The damaged exposed surface of the rotor blade leads to an increase in drag forces on the rotor blade, which can cut the production of electricity by $20 \%$ per year. These damage mechanisms occur in two ways, firstly by droplet water hammer pressure, which leads to pit formation and secondly water lateral jetting and development of shear waves, which results in delamination of exposed surface material $[10,19-22]$.

Moreover, it is well established in the literature that when a droplet impacts a solid surface compressive and shear waves are produced. These waves work through the solid materials and a Rayleigh wave move across over the surface of the specimen. The intensity of the Rayleigh wave depends on the diameter of the droplet and its impact speed. The highest 
component of the impact energy is acquired by these waves. When a droplet strikes the exposed surface, the liquid spreads laterally at a very high-speed along the radius of the droplet following the Rayleigh wave. The simultaneous effects of lateral jetting and Rayleigh wave create stress on the exposed surface lead to delamination in the composite material [23].

The angle of attack has a significant effect on the erosion behaviour of this composite Fig. 3 . It plays an important role in the characterisation of erosion mode and mechanism of a material. According to the erosion theory, advanced by Bitter, at an angle of attack up to < $10^{\circ}$, the erosion is progressed by the cutting process of the erodent. At $90^{\circ}$ angle of attack, deformation of the exposed surface is progressed by impact action, while for the range of angle of attack between $10-90^{\circ}$ erosion occurs with the combination of impact and cutting mechanism $[24,25]$. Though this theory was developed for the erosion of solid particle, the SEM images show that the erosion by droplets is likely to follow this pattern. At $90^{\circ}$ impact angle, Fig. 5, the mechanisms of erosion are the propagation of cracks and flaking away of material from the exposed surface of the specimen. Erosion is dominated by the impact of droplets at higher angles of attack, which leads to degradation of the targeted surface [26].

The surface morphology of the exposed surface due to droplet erosion depends on the angle of attack and impingement speed of the droplet [27]. At a lower angle of attack, test samples are more susceptible to ploughing and shearing under jetting effects of the droplets [23]. Generally, it has been concluded that the $90^{\circ}$ component of the droplet impact speed results in deformation. The component parallel to the surface of the blade negligibly adds to erosion. Hard materials, such as ceramics and rigid polymers, may behave differently. At a very high impacting speed, the tangential component of the droplet impact speed may result in a higher damaging of the rotor blades $[22,26]$.

Moreover, the significant mass loss for all solutions is attributed to the size of the droplet in this case. Large size droplets may result in a higher and faster rate of erosion due to large hammering effect on the blade surface. The distribution of the droplet pressure varies over the exposed region. Researchers have attempted to establish the dependence of droplet impact speed, size, and erosion rate, but in vain. However, it has been concluded in the literature that as the impact speed increases the rate of erosion increases [28-30]. 


\subsection{Erosion map}

Erosion maps indicate the level of degradation of the blade material for the range of operating conditions. This map can help in the understanding the mode erosion degradation, designing, to identify the safe and unsafe operating conditions, and to enhance the performance of a rotor blade of the wind turbine applications [5,31,32]. The erosion mode map is split into 3 distinct regions as low, medium and high erosion levels Fig. 9. This has been constructed for different combinations of (rainwater) $\mathrm{pH}$ and a range angles of attack. The erosion regime boundaries have been estimated in view test results and are presented by the level of mass loss as below:

1. Low $\leq 6 \times 10^{-4} \mathrm{~g}$

2. $6 \times 10^{-4} \mathrm{~g}<$ Medium $\leq 10 \times 10^{-4} \mathrm{~g}$

3. $10 \times 10^{-4} \mathrm{~g}<\mathrm{High}$

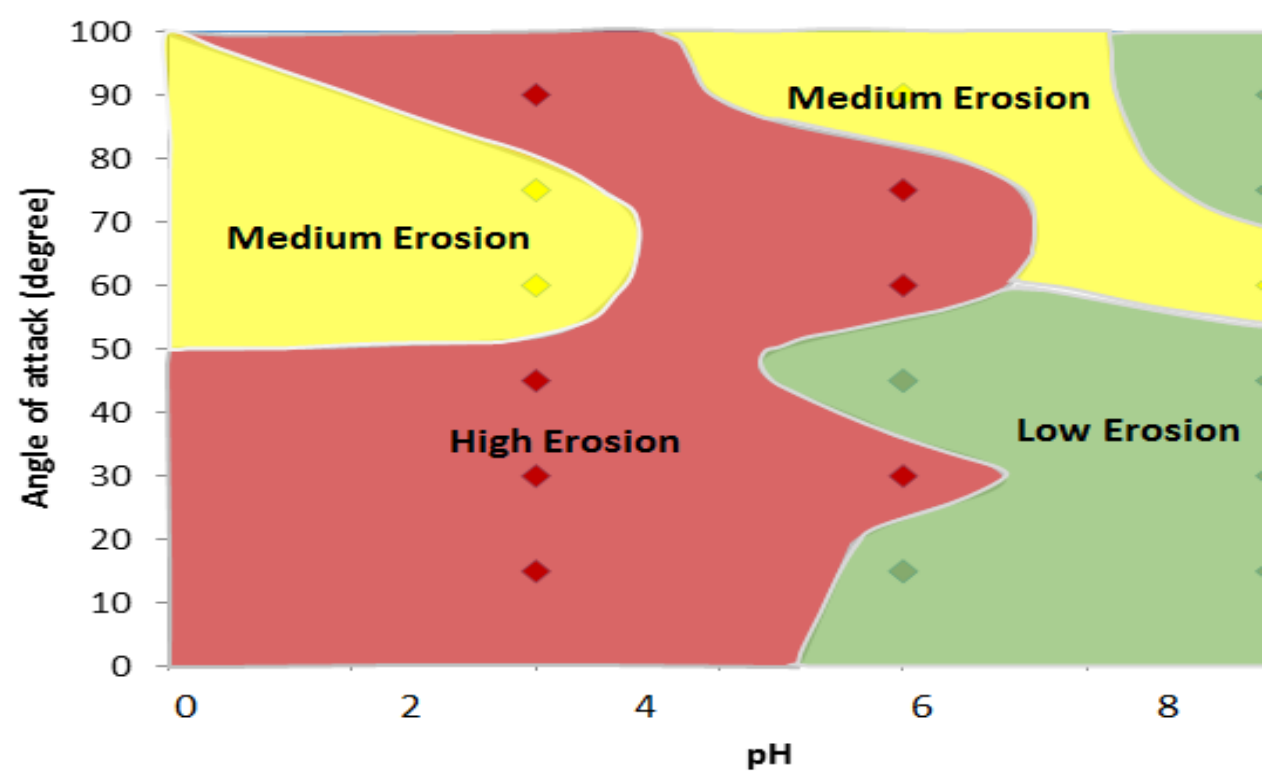

Figure 9: Erosion map for the $\mathrm{pH}$ of various rainwater solutions versus impact angles

In this experimental window, GFRE polymeric composite is showing a higher erosion in an acidic rain for the range of impact angles. Interestingly, the deionised water shows a similar mass loss trend as that of the acidic water. For an acidic solution, $\mathrm{pH} 4$, the erosion mass loss increases, whereas for the salt solution, $\mathrm{pH} 8$, mass loss decreases. The lower mass loss of the specimens in saline solution is attributed to the absorption of saltwater. It can be concluded from these results erosion is dominated by the mass loss for the acidic solution and by gaining mass by salty solutions. Both conditions are unacceptable for the wind turbine blade as these 
can result in accelerated leading-edge erosion as well as unbalance operation of the rotor blades.

Fibre-reinforced polymer matrix composites are a good choice for the manufacturing of wind turbine blades. These composites have good mechanical properties and a higher strength-todensity ratio. The leading edge erosion and mass gain resistance of these composites can be enhanced by the application of suitable surface protection layers, i.e. erosion resistant coatings. Future experimental work will be carried out on different types of erosion-resistant coatings to enhance the erosion resistance for the wind turbine blade material in different environments, i.e. onshore and offshore polluted environments.

\section{Concluding Remarks}

1. The raindrop erosion behaviour of materials depends on various factors, such as material type, exposure conditions, mechanical properties, impact velocity, impact angle, and droplet size. Maximum wear was recorded at $15^{\circ}$ impact angle in an acidic rainwater solution.

2. The glass fibre reinforced polymeric composite does not show any specific traditional erosion behaviour, i.e. the erosion peak patterns of a higher mass loss at $30^{\circ}$ for so-called ductile materials and higher mass lass at $90^{\circ}$ for brittle materials. This erosion behaviour is consistent with observed patterns of erosion of other fibre reinforced polymer composites.

3. Exposed surface cracks, gouges, blistering leading to exposure of fibres all contributed to the erosion mechanisms.

4. Further research work is required in this area to explore suitable erosion resistant coatings, which are capable of withstanding harsh environments at higher rotor blade tip speeds.

\section{Acknowledgements}

The authors would like to acknowledge the support of the Interreg (Northern Ireland - Ireland - Scotland) Special EU Programmes Grant No SPIRE2_INT - VA - 049 "Storage Platform for the Integration of Renewable Energy (SPIRE 2)". 


\section{References}

[1] Keegan, M. H., Nash, D. H., and Stack, M. M., "Modelling rain drop impact on offshore wind turbine blades," In: ASME Turbo Expo 11- 15 June 2012.

[2] Dr Conti-Ramsden, J., and Dr Dyre, K., "Materials innovations for more efficient wind turbine, Renewable energy focus com," http://www.renewableenergyfocus.com/view/42937/materialsinnovations-for-more-efficient-wind-turbines/, 21 September 2015.

[3] Pugh, K., Rasool, G., and Stack, M. M., "Some thoughts on mapping tribological issues of wind turbine blades due to effects of onshore and offshore raindrop erosion," J Bio Tribo Corros (2018) 4: 50. https://doi.org/10.1007/s40735-018-0165-9.

[4] Huang, G., "Behaviors of glass fiber/unsaturated polyester composites under seawater environment," Material and Design (2009) 30 (4), pp. 1337-1340.

[5] Rasool, G., and Stack, M. M., "Some views on the mapping of erosion of coated composites in tidal turbine simulated conditions," Journal of Tribology Transactions, Volume 62, 11 April 2019, Pages 512-523, DOI: 10.1080/10402004.2019.1581313.

[6] Rasool, G., Sharifi, S., Johnstone, C., and Stack, M. M., "Mapping synergy of erosion mechanisms of tidal turbine composite materials in sea water conditions," Journal of Bio- and Tribo-Corrosion, DOI: 10.1007/s40735-016-0040-5, June 2016, 2:13.

[7] Joeng-Ho, K., Cho, H. G., and Park, Y. K., "The Effect of Acid Rain on the Tracking Resistance of Polymeric Insulating Materials," Proceedings of the 5uL International Conference on Properties and Applications of Dielectric Materials May 25-30,1997, Seoul, Korea 02P21.

[8] Amaro, A., Reis, P., Neto, M., and Louro, C., "Effects of alkaline and acid solutions on glass/epoxy composites, Journal of Polymer Degradation and Stability," DOI: 10.1016/j.polymdegradstab.2012.12.029.

[9] Zhou, R., Lu, D. H., Jiang, Y. H., and Li, Q. N., "Mechanical properties and erosion wear resistance of polyurethane matrix composites," Wear 259 (2005), pp 676-683.

[10] Keegan, M. H., Nash, D. H., and Stack, M. M., "Topical Review: On erosion issues associated with the leading edge of wind turbine blades," Journal of Physics D: Applied Physics, 46 (38), ISSN $0022-$ 3727, http://dx.doi.org.10.1088/0022-3727/46/38/383001.

[11] Ahmed, M., Schatz, M., and Casey, M.V., "An empirical approach to predict droplet impact erosion in low-pressure stages of steam turbines," Wear 402-403 (2018), pp 57-63. 
[12] Zou, J., Zhu, Y., Pan, M., Xie, T., Chen, X., and Yang, H., "A study on cavitation erosion behavior of AlSi10Mg fabricated by selective laser melting (SLM)," Wear 376-377 (2017), pp 496 - 506.

[13] Zhu, J. Z., Zhao, W. L., Chen, X. Y., and Yang, H. Y., "A study on surface topography in cavitation erosion tests of AlSi10MgY," Tribology International 102(2016), pp 419 - 428.

[14] Macdonald, H., Stack, M. M., and Nash, D. H., "The influence of hail on wind turbine blade leading edge erosion and damage," Student thesis: Doctoral Thesis, University of Strathclyde UK, https://pureportal.strath.ac.uk/en/studentTheses/the-infuence-of-hail-on-wind-turbine-bladeleading-edge-erosion-a.

[15] Keegan, M. H., Nash, D. H., and Stack, M. M., "Wind Turbine Blade Leading Edge Erosion: An Investigation of Rain Droplet and Hailstone Impact Induced Damage Mechanisms," University of Strathclyde 2014.

[16] Hutchings I.M., "Some comments on the theoretical treatment of erosive particle impacts," Proceedings of the Fifth International Conference on Erosion by Liquid and Solid Impact, Pub. Cavendish Laboratory, (1979) paper 36.

[17] Lee, M. Ku., W. Kim, W., Rhee, C. K., and Lee, W. J., "Liquid impact erosion mechanism and theoretical impact stress analysis in TiN-coated steam turbine blade materials, Metallurgical and Materials Transaction," April 1999, Volume 30, Issue 4, pp. 961-968.

[18] Jana, B. D., and Stack, M. M., "A note on threshold velocity criteria for modelling the solid particle erosion of WC/Co MMCs," Wear, Vol. 270, no. 7-8, PP. 439-445, March 2011.

[19] Ducom Instruments, Investigation of rain droplet erosion of turbine blade materials in the lab, https://gallery.mailchimp.com/380881cace4a4bd8862cb2561/files/6653d2a0-1ea7-4a9a-

98cf0ae76070094b/AR 33 Investigation of rain droplet erosion of turbine blade materials in $t$ he lab.pdf.

[20] Sareen, A., Sapre, C., and Selig, M., "Effects of leading edge erosion on wind turbine blade performance," Research Article, Published online 12 July 2013, DOI: 10.1002/we.1649.

[21] Reder, M. D., Gongalez, E., and Melero, J. J., "Wind turbine failures - Tackling current problems in failure data analysis," Journal of Physics: Conference Series 753 (2016) 072027.

[22] Gaudern, N., "A practical study of the aerodynamic impact of wind turbine blade leading edge erosion," 2014 J. Phys.: Conf. Ser. 524012031. 
[23] Gohardani, O., "Impact of erosion testing aspects on current and future flight conditions," Prog. Aerosp. Sci. 47(2011), pp 280-303.

[24] Amarendra, H. J., Chaudhari, G. P., and Nath, S. K., "Synergy of cavitation and slurry erosion in the slurry pot tester," Wear (2012), Vol. 290-291, Pages 25-31.

[25] Levy AV (1995), "Solid particle erosion and erosion-corrosion of materials," ASM International, Novelty, Pages 220.

[26] Mens, J.W.M., and de Gee, A.W.J., "Erosion in seawater slurries," Tribology International, Vol. 19, issue 2, April (1986) PP. 59-64.

[27] Charles, B., Thomas, B., Harvey, T., and Wood, R, "Water droplet erosion of aero-engine fan blades: The importance of form," Wear, 426-427(Part A), 507-517.

[28] Engel, O.G., "Mechanism of rain erosion," Wright Air Development Centre, USA. Report No. 53192 (1953) 1-54.

[29] Brunton, J.H., and Rochester, M.C., "Erosion of solid surfaces by the impact of liquid drops," in: C.M. Preece (Ed.), Treatise on materials science and technology, Academic press, New York, 1979, 186 248.

[30] Adler, W.F., "The mechanics of liquid impact," in: C.M. Preece (Ed.), treatise on materials science and technology, Academic Press, New York, 1979, 127-185.

[31] Rasool, G., Mridha, S., and Stack, M. M., "Mapping wear mechanisms for TiC/Ti composite coatings," Wear, Volumes 328-329, 15 April 2015, Pages 498-508.

[32] Inman, I. A., Rose, S.R., and Datta, P. K., "Development of a simple 'temperature versus sliding speed' wear map for the sliding wear behaviour of dissimilar metallic interfaces," wear 260 (2006) 919-932. 